\title{
Computing students learning outcomes in learning by developing action model.
}

\author{
LINTILÄ, T. and ZARB, M.
}

2020

IATED preferred citation T. Lintilä, M. Zarb (2020) COMPUTING STUDENTS LEARNING OUTCOMES IN LEARNING BY DEVELOPING ACTION MODEL, ICERI2020 Proceedings, pp. 1936-1945. 


\title{
COMPUTING STUDENTS LEARNING OUTCOMES IN LEARNING BY DEVELOPING ACTION MODEL
}

\author{
Taina Lintilä ${ }^{1}$, Mark Zarb² \\ ${ }^{1}$ School of Computing, Robert Gordon University (UNITED KINGDOM) \\ ${ }^{2}$ School of Computing, Robert Gordon University (UNITED KINGDOM)
}

\begin{abstract}
This article describes a study to understand how suitable the Learning by Developing (LbD) action model used in Laurea University of Applied Sciences (Laurea) is as a teaching and learning method for computing students. The study also aims to obtain computing students' perception on the development of competencies in different areas and students, lecturers and customers' common experiences about the LbD. The purpose of the study is also to utilize the research results in the development of the LbD action model. Both staff and student perceptions of this action model are found to be positive.
\end{abstract}

Keywords: Learning, teaching, Learning by Developing, computing, learning outcomes.

\section{INTRODUCTION}

The purpose of the study is to find out the perception of computing students with a study module implementation based on the Learning by Developing $(\mathrm{LbD})$ action model used in Laurea University of Applied Sciences (Laurea) in Finland. The aim of the study is to find out how the students' competence develops during the study module and what are they general experience of learning according to the LbD action model. The LbD action model has been developed in Laurea by closely examining teaching and learning in Universities of Applied Sciences [1]. The LbD action model has been used at Laurea since 2004 and it has been shown to be a successful way to teach new things in higher education [2]. Studies on the LbD based learning in Laurea have been conducted among students in social sciences and health care, but not very comprehensively among STEM students, including computing. In the LbD action model it is considered essential to learn new ways to act and to renew work life.

The aim of this study is to obtain information on whether the LbD action model is a good learning and teaching method for Laurea computing students' study modules involving real-world projects. Computing students have been chosen as the research topic because studies that only examine the experiences of computing students in teaching according to the LbD action model have not been conducted before. An important subject of the study, besides the student's own learning experiences, is how their problem-solving skills and other competencies developing in the LbD action model projects that have been implemented in co-operation with the working life. The study also examines the lecturers' experiences of using the $\mathrm{LbD}$ action model and its suitability for computing studies, as well as the experiences of the clients involved in the study module on using the $\mathrm{LbD}$ action model in real customer projects.

\section{METHODOLOGY}

The strategy of this research has been chosen as action research because it is well suited for development-based research, where the researcher is him/herself part of the organization being developed. The action research is a discipline-based research conducted by a teacher, the purpose of which is to obtain information and, on the basis of the information received, to change his or her practice in the future [3]. In this process, participants systematically and carefully review their own teaching practices using research methods [4]. Action research is well-suited to educational research and can involve just a single teacher, a group of teachers with a common problem, or the entire school faculty [5].

The action research proceeds periodically, starting from the situation under study. Based on the information being researched, the researcher gets a picture of the current state and on the basis of it, he or she sets out to plan the target state. The researcher participates in the development process, reflects on the situation with other participants and further develops it. In this study, the first cycle was conducted at Laurea in the autumn of 2019 with a further cycle being planned with staff and students 
from a university in the United Kingdom, to ascertain whether the LbD approach is also suitable for computing students outside of Laurea. Method triangulation is used as the main research method in this study. Method triangulation means, for example, that several data acquisition methods are used in the acquisition of research material [6]. The data collection methods used in this study are both a survey conducted for students and a thematic interview conducted for lecturers and clients. In addition, research data have been collected from students from the learning diaries they made during the study module. As a method of analysing research data, data-driven content analysis is used for thematic interviews and free-form questions from students. When conducting data-based research, the main emphasis of the research is on the data, which means that, for example, the analysis units are not predetermined and the theory is built on the data as a starting point. In this case, one can speak of inductance, which means the progression from individual observations to more general claims [6]. The starting point of the inductive approach is therefore not the testing of theory or hypotheses, and the researcher does not determine what is important [7]. Students' quantitative responses are analysed using means and standard deviations.

\section{RESULTS}

The subjects of this cycle of research were computing students who participated in the Service Design study module conducted at Laurea in the autumn of 2019, which lasted for 16 weeks. 32 undergraduate students participated in the study module. The teaching method used in the study module was the LbD action model, which has been chosen as Laurea's general teaching and learning method. The Service Design study module was chosen as the subject of the study because students participate in a project implementation related to the development of working life in cooperation with a genuine client [8].

During the study module, students did a mixture of independent assignments and group assignments, as well as a development project related to working life in cooperation with the client. At the beginning of the study module, the researcher introduced the students, customers, and the lecturer of the study module to the $\mathrm{LbD}$ action model and explained what it means in practice. Students were told that at the end of the study module, the researcher would conduct a survey, the results of which would be used for research purposes. Clients were asked if they could participate in an interview after the study module, which is also related to this same study. The researcher's colleague had also been asked for permission to participate in the interview.

The aim of the study was to obtain information on how students' skills develops during the study module and what are their learning experiences with the implementation of the study module according to the LbD action model. In particular, the purpose of this study is to obtain information on whether the LbD approach is a good and workable way for students to study computer science and how well it is suitable for this purpose. Answers to these questions are sought in the study, in addition to the student survey, but also through interviews with lecturers using the LbD approach. Information was also collected from customers through interviews. They were asked about their experiences of their participation in the implementation of the $\mathrm{LbD}$ action model study module in the role of the customer.

At the beginning of the Service Design study module, students were also asked to keep a learning diary in accordance with the instructions given in the assignment, which is also included as research data for the study. Thus, research data were collected in many ways: from student learning diaries, student surveys, interviews with clients and lecturers. A survey of students and interviews with clients and lecturers were conducted at the end of the study module, at the end of 2019 and at the beginning of 2020. The student questionnaire included questions classified according to the Likert scale, as well as free-form questions. 29 of the 32 students returned their learning diaries at the end of the study module.

Interviews with clients and lecturers were conducted as thematic interviews using an online tool. The interviews were recorded and later transcribed for further analysis. Customer interviews were conducted for all six participants and lecturer interviews were conducted for three. One of the lecturers taught together with the researcher for the study module under study. Two other lecturers who simultaneously had a similar service design study module for business management students were also selected for the interview in order to obtain more data.

\subsection{Students' survey}

The development of students' competence was mapped using several questions, which are based on the university's competence areas defined in Laurea's strategy for 2030 [9]. Laurea has strongly identified the skills needs of working life alongside the degree's substantive skills and they are perceived 
as increasingly important skills for those who have completed applied sciences higher education. These Laurea general working life skills which are common to all degrees consist of six competencies: selfmanagement and entrepreneurial attitude, critical thinking and problem-solving skills, foresight and innovation skills, communication and interaction skills, global skills and responsibility skills. These competency developments in all studies and were therefore taken as the basis for a survey of students.

Each set of competencies contains three or four more detailed sections, the development of which is assessed by the students in the survey. In the questionnaire, students did a self-assessment of the topics in each area by assessing what their level of competence was in each section before the start of the study module and what they thought was their level of competence at the end of the study module. A few examples of these results have been raised here. In interpreting the answers, it should be noted that this is a self-assessment undertaken by the students. This is presented as a limitation on the reliability of the results.

\subsubsection{Students; surveys results to classified questions}

The first set of competences was self-management and entrepreneurial attitude and the first section in that set was life management and well-being. Students were asked to rate their own competence in each subject area on a scale of 1 ("no competence") to 5 ("expert"). The results can be seen in Figure 1. The average of students' own competence at the beginning of the study module was 3.34 and the standard deviation was 0.84 . The average of students' own competence at the end of the study module had risen to 3.69 and its standard deviation is 0.75 , so the variance had decreased at the end of the study module.

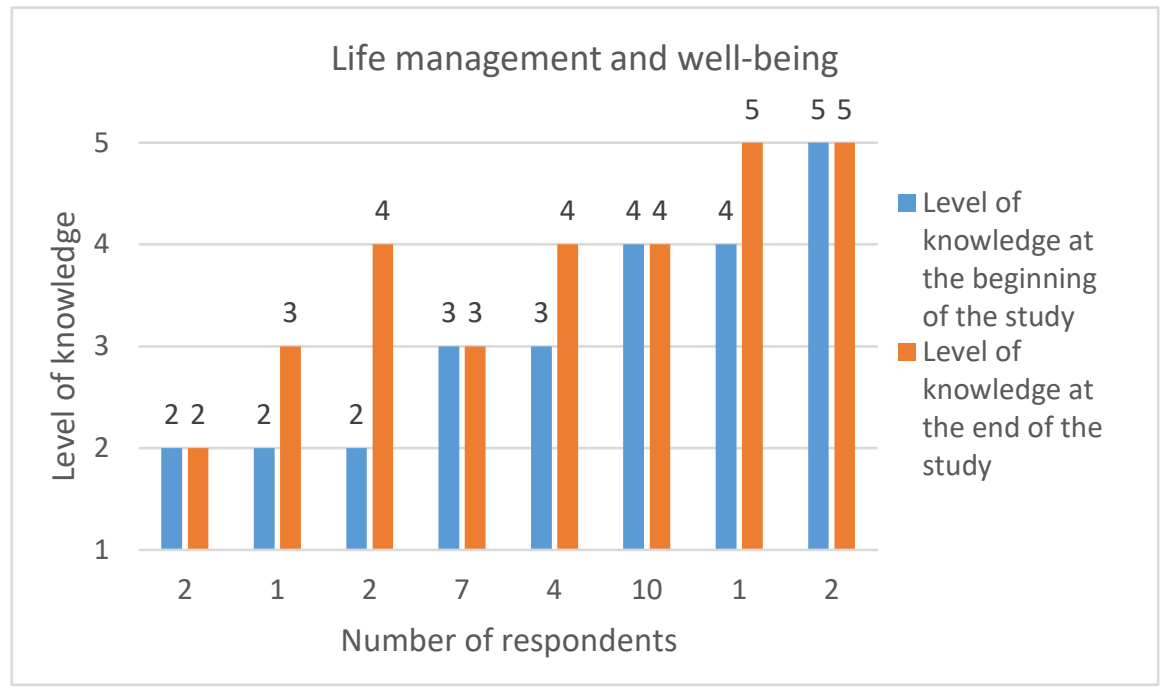

Figure 1. Students' survey results for Life management and well-being.

Students were also asked to rate how well they felt they were able to self-assess their own competencies and what their continuous learning abilities were. The results are depicted in Figure 2.The reported mean was 3.07 at the beginning of the study module and 3.76 at the end. The standard deviation was 0.78 at the beginning of the study module and 0.73 at the end of the study module. The change was not significant, but the variance had decreased here as well. 


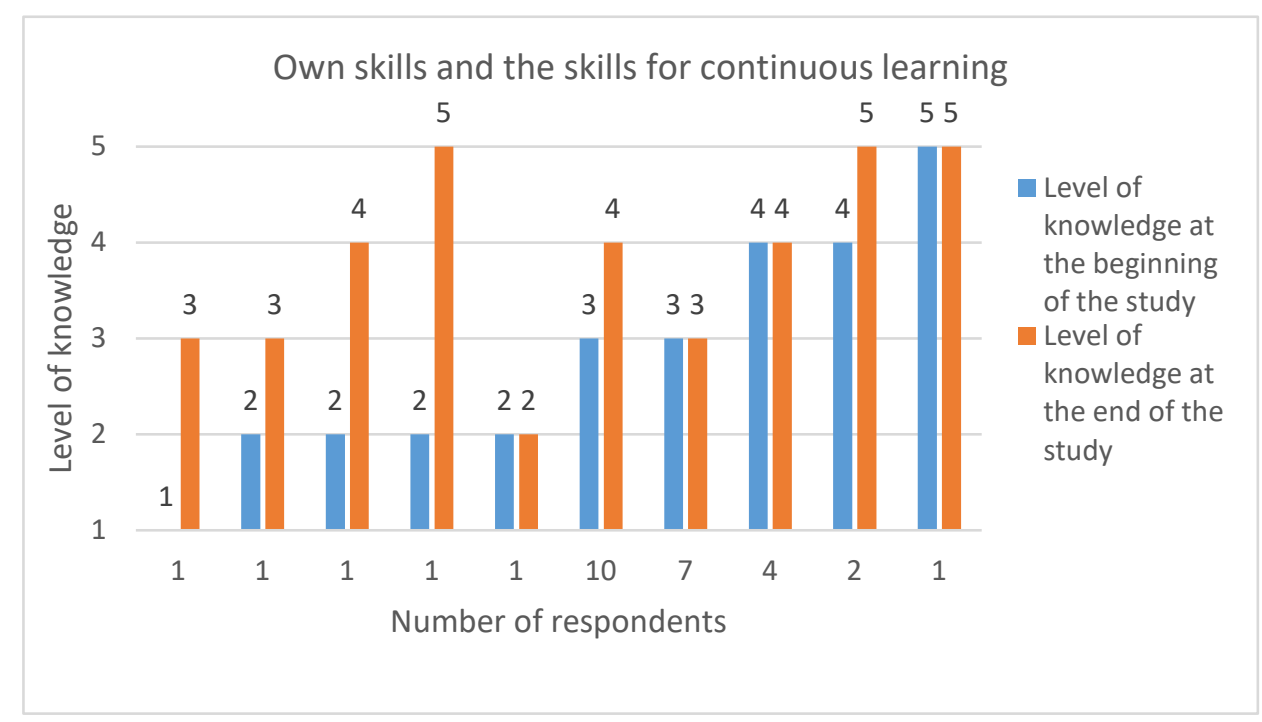

Figure 2. Students' survey results for Own skills and the skills for continuous learning.

The second set of competences was critical thinking and problem-solving abilities, which included three points to be assessed. The results are reported in Figure 3. The mean of these answers was 3.21 at the beginning of the study module and 3.79 at the end of the study module. The standard deviation was 0.66 at the beginning of the study module and 0.61 at the end of the study module, so even here the variance had decreased slightly at the end of the study module.

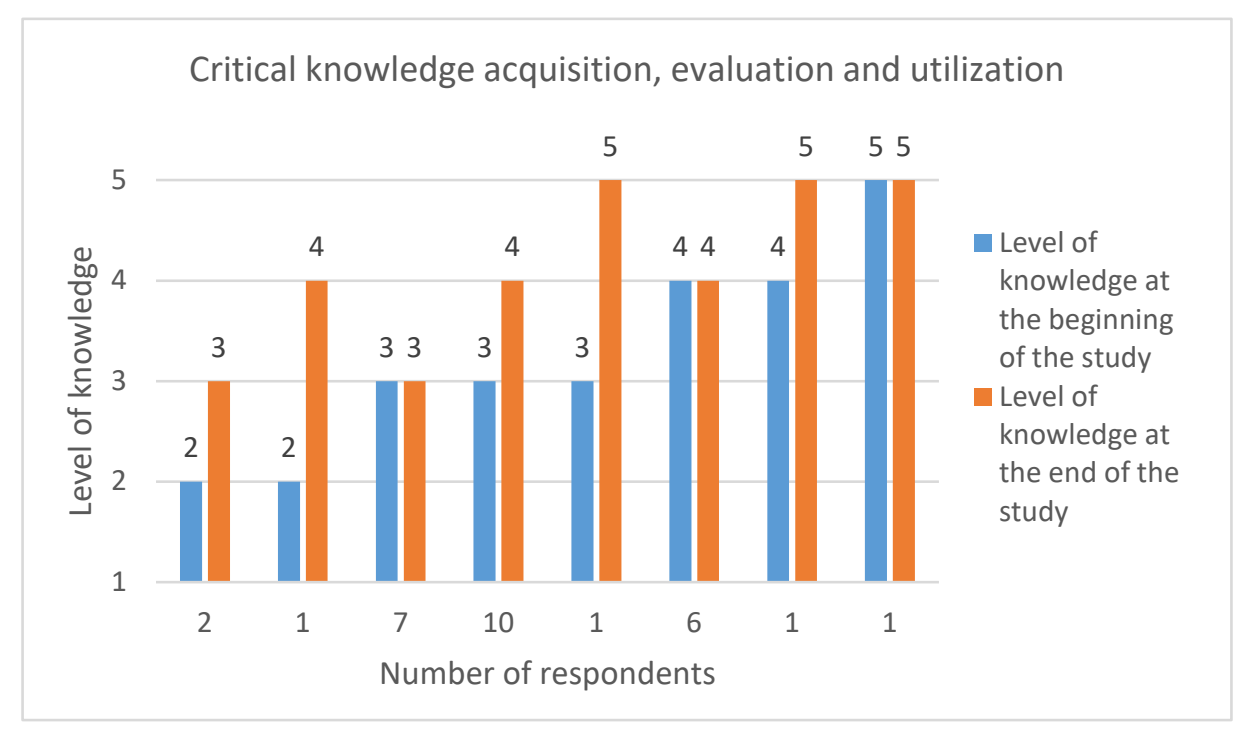

Figure 3. Students' survey results for Critical knowledge acquisition, evaluation and utilization.

The next question in this section was the entity management and systematics. The results are reported in Figure 4. The reported mean in these answers was 2.69 at the beginning of the study module and 3.21 at the end of the study module. There was quite a lot of variance in these answers and the standard deviation were 1.02 at the beginning of the study module and 1.13 at the end of the study module. Four students rated the starting level as 1, i.e. no competence at all and according to their own assessment it did not increase during the study module. This would be interesting to study further, as this is an important skill for students and it also helps the student to manage their own studies and is also an important skill in working life. 


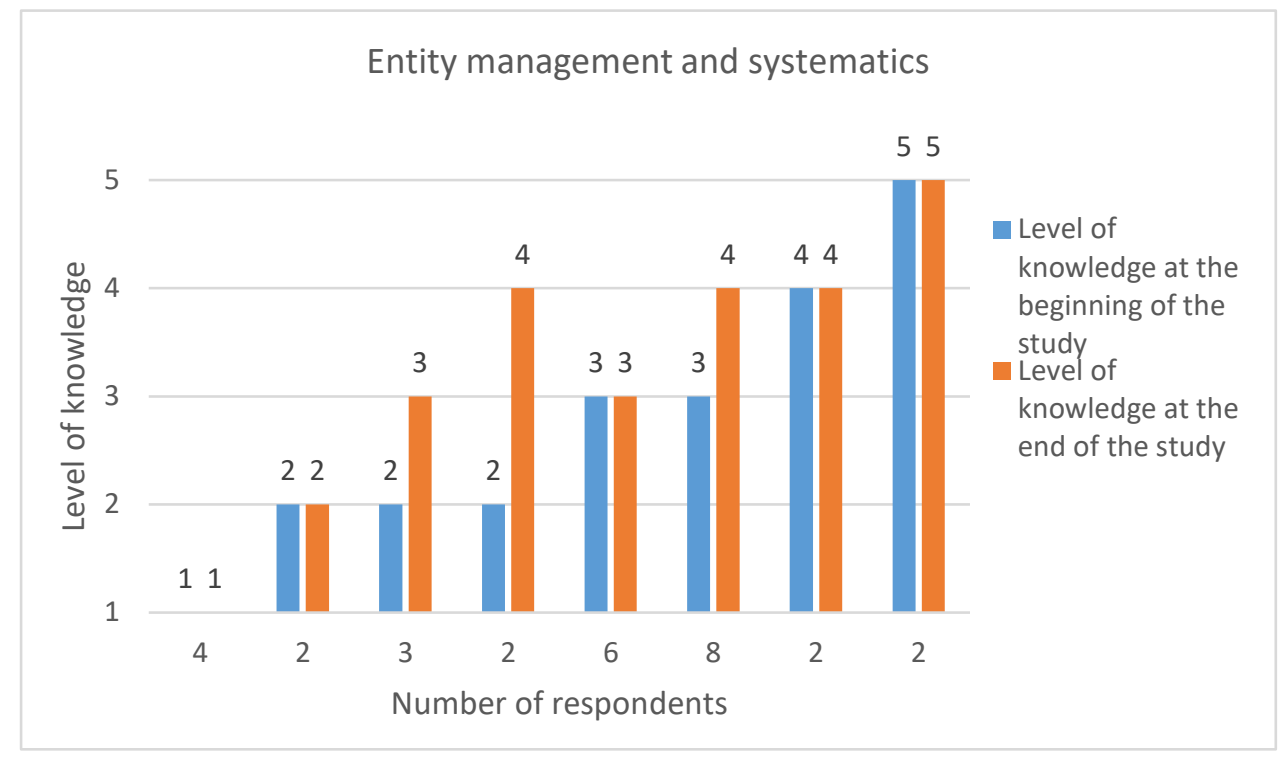

Figure 4. Students' survey results for Entity management and systematics.

The third issue at this point was analytical thinking and argumentation. The results are reported in Figure 5. The reported mean at the beginning of the study module was 3.34 and 16 students had chosen starting level 3. Half of them estimated that their starting level had risen to level 4 during the study module and the average at the end of the study module was 3.69. 10 students chose to start level 4 and they all rated their level as staying the same. One student estimates that his starting level was already at the highest level. The standard deviation in these answers was 0.66 at the beginning of the study module and 0.53 at the end of the study module, i.e. the variance decreased at the end of the study module.

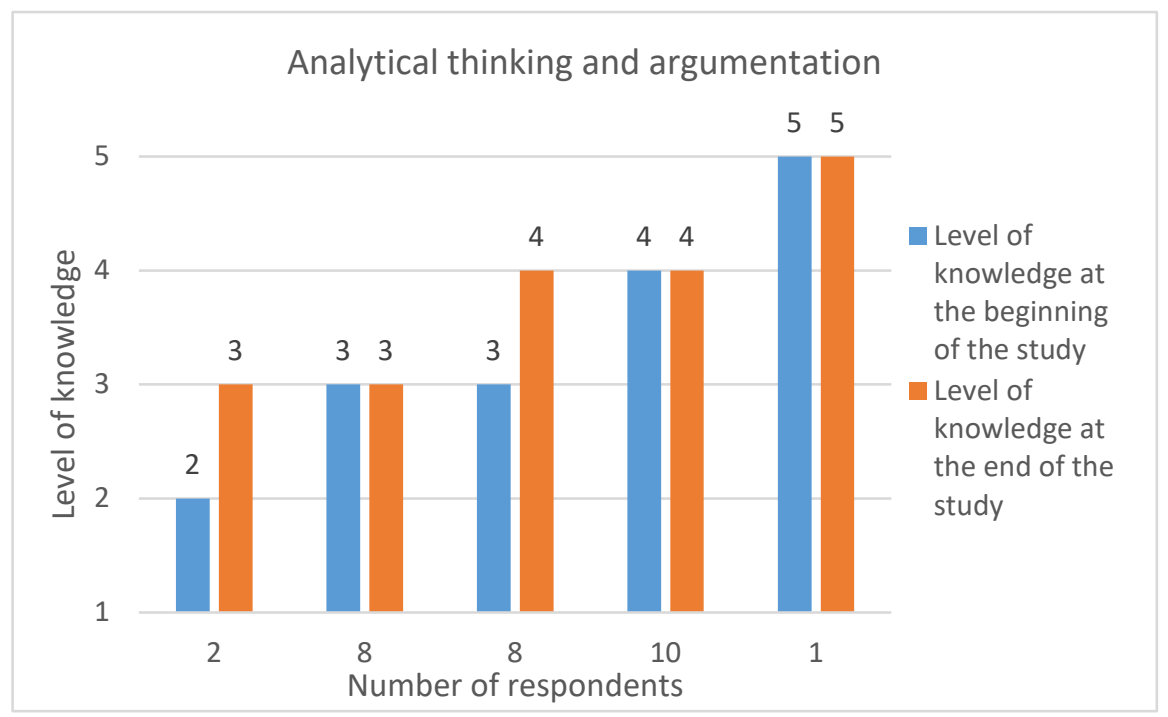

Figure 5. Students' survey results for Analytical thinking and argumentation.

This is a small but interesting sample of the results of the study. A more detailed analysis of the results is still ongoing and will be compiled into a final study that will analyse the research results more broadly. 


\subsubsection{Students' survey answers for free-form questions}

In addition to numerical self-assessments, students were also asked to respond freely to what new things or skills they learned during the study module. The students' verbal answers are analysed in more detail using the content analysis method as the research progresses, but this is a compilation, by way of example, of the students' answers to a few questions posed in the questionnaire.

The first free response question was: What new things and/or skills did you learn during the study module? Here are a few authentic answers given by students:

"Working in a multicultural environment (with other nationalities and other age range than me); developing a service WITH the customer and not FOR the customer (the principle of service design and co-creation); to implement agile method in order to provide a service which will interest people"

"I learned a lot about working with people I don't know beforehand and working with a difficult project assignment. And many other skills."

"Combining different already learnt things together with new ways"

"Creating a well customer oriented service".:

"Service design methods and how to use these in a project"

"More in depth usage of different agile methods"

"The importance of including the customer/user in the development process"

"How to work with different people for other cultures and use that as strength."

"I would say that I have learn to trust more in my own opinions and solutions and not always doubt myself and my capability."

"Different skills in teamwork and different development methods".

Most of the students indicated that they had learned things in accordance with the objectives of the study module. The topic of the study module was service design and agile methods, and during the study module the groups participated in a genuine customer project. The customer projects were all different and the content of the projects, of course, influenced what was emphasized in each project and what things were learned there. In this study module was also attended exchange students and they were divided in all groups, so that there was at least one foreign student in each group, so that working with people from different cultures also became familiar in each group. One of the participants did not answer this question at all and one student answered that they did not learn anything new in this study module.

Students were also asked how well they felt they understood what LbD meant in practice. The scale was 1 ("no understanding") to 5 ("very good understanding"). It can be seen from the Figure 6 that more than half of the respondents felt that they understood the meaning of $\mathrm{LbD}$ well in practice. Only two students answered that their level of understanding was 2, i.e. not very high. Students were also asked to verbally describe what the $\mathrm{LbD}$ approach means in practice.

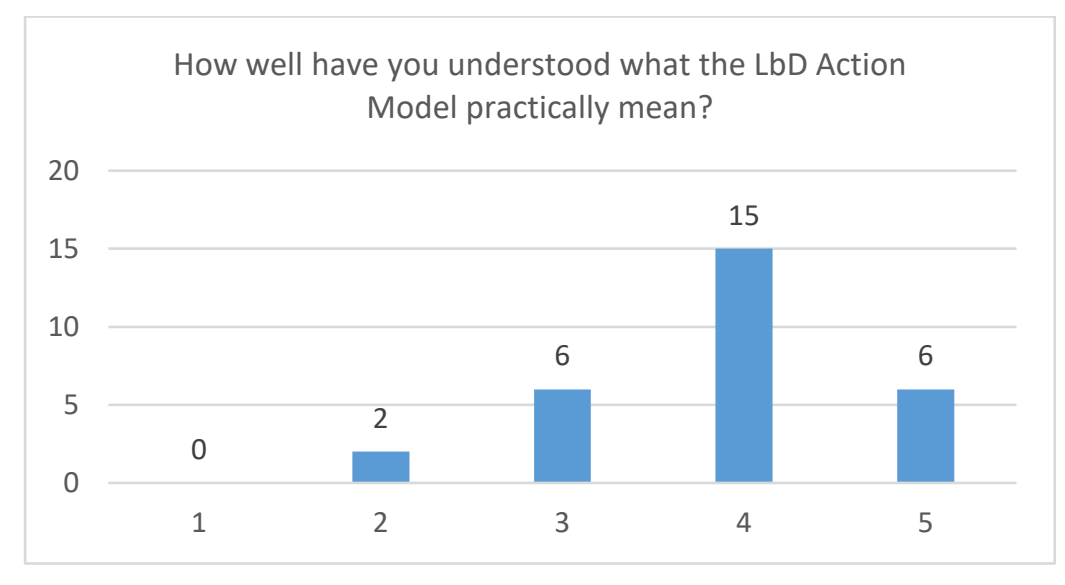

Figure 6. Students' own opinion of understanding what the $L b D$ approach means in practice. 
The responses to numerical self-assessments versus verbal descriptions are partially contradictory. However, for example, two students who rated their understanding as level 2 had verbally been able to describe well what $\mathrm{LbD}$ means in practice. Six students had rated their understanding at level 5 , but based on verbal responses, 4 of them had not correctly understood what LbD means in practice.

Students were also asked how appropriate they felt $\mathrm{LbD}$ is in computing science studies. It can be seen from the Figure 7 that most students think it fits well or quite well. From the verbal responses, it can be seen that students feel that $L b D$ helps to assimilate and internalize things better because they are applied in practice during the study module, rather than studying things only through theory.

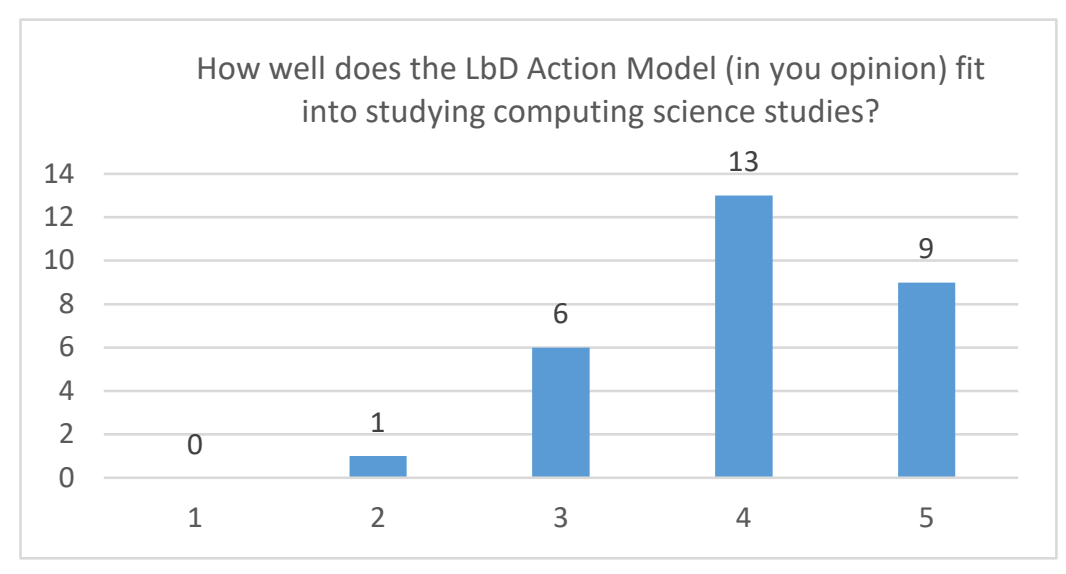

Figure 7. Students' own opinion how well does the $L b D$ fit into computing studies.

Here are a few authentic answers to the question: How well does the LbD action model (in your opinion) fit into studying computing science studies?

"It is, since computing science often includes developing services, products and what not and those are done by working in teams. So it really prepares students for their future jobs."

"Because it's a domain in which doing the things practically is better"

"Because the best way of learning computing science is doing not just reading theory"

"In every study, $L b D$ is a good method, but it shouldn't be the only method of learning. If studies are only in the classroom, theory, it is more like university teachings. Today, companies need workers who have skills and know-how of real working life before they graduate."

"Suits perfectly because in computing science the best learning outcomes occur when trying things out and learning by successes and mistakes."

Only one student thinks that $L b D$ is not very suitable for computing studies. There are a number of factors which could have contributed to this, including overall disengagement with the study module, however, these responses were forwarded to the study team for further analysis.

Students were also asked how well in their opinion the LbD fit into this Service Design study module. It can be seen from the Figure 8 that the distribution in terms of the answers is quite similar to what it was in terms of computing studies. 


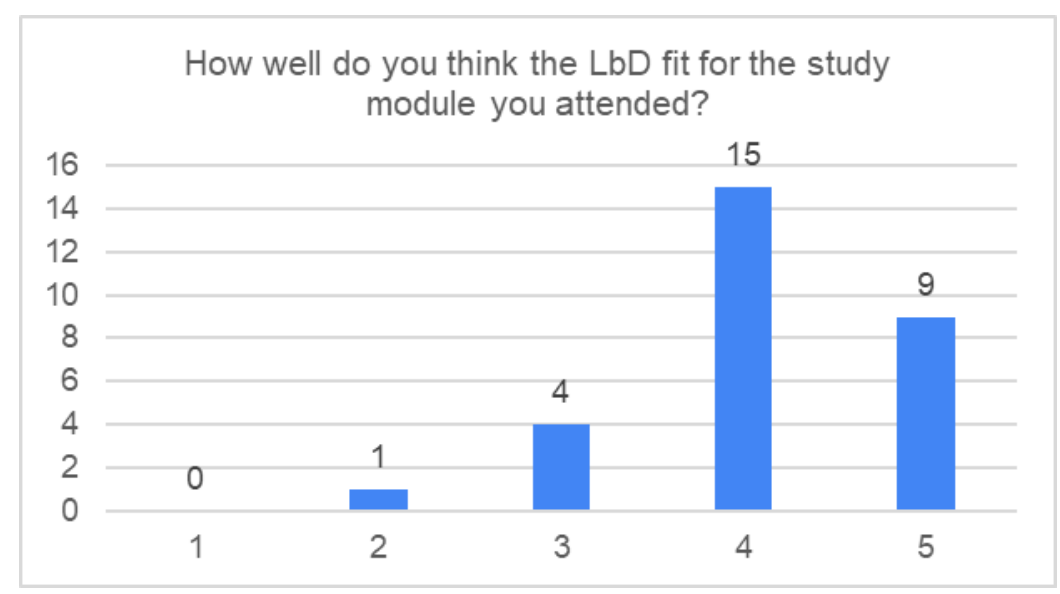

Figure 8. Students' own opinion how well, does the LbD fit into the Service Design study module.

From the verbal answers, a few answers have been compiled here, which opens this issue well from the students' point of view:

"It was really efficient and I know that I'll remember what I learned in this module for a long-time!"

"I think this model fitted on this module very well"

"Fits good, as also creativeness is important"

"With service design, the best method to understand is, is to take company representative to the process. It is a textbook example of service design (take customer along to the decision making...)"

"Suited well because we had to research thing on our own and then put them on use so we had to really also understand the subjects."

"There is many things on handling a project that cannot be understand without actually using them. Also it helps to learn also new tools, software and methods when u can create something. It is always more rewarding to see your achievements."

"Working with a customer was fun and a learning experience, creating something based on their needs. I don't think this study would've been as effective without them"

"I think that the service design study unit is just perfect for $L b D$ model, because of the using $L b D$ makes learning many topics that were part of this study unit easier. It gives the students a great opportunity to do a project with a real client where they can utilize information that they learned during the study unit."

"The study module was intended to give students a slightly more comprehensive look at agile development and service design techniques, so trying it all out in a project from an outside customer seems like a practical way to do it."

Based on these responses, it can be concluded that most of the students felt that the LbD approach was well suited for a study module like this and that they felt that they had learned and embraced things more deeply, as they were able to apply what they learned in practice in real customer projects.

\subsection{Interviews of lecturers and customers}

The study also collected research data from the Service Design study module lecturers through thematic interviews. As the researcher herself worked as a lecturer in that study module, thematic interviews were also conducted with two other lecturers who have at the same time the Service Design study module for business management students. The aim of the study was to find out what kind of experiences the lecturers themselves have when using the $\mathrm{LbD}$ action model in teaching and how suitable teaching method it is for the Service Design study module in their own opinion. The thematic interviews were conducted remotely and transcribed so that the responses could be analysed in more detail. This article only discusses the lecturers' answers related to their experiences of using the LbD and its suitability for 
the Service Design study module. The interviews were conducted in Finnish. For the purposes of this paper and its international audience, they have been translated to English by a native speaker.

When asked "How suitable do you think LbD is for teaching the Service Design module?", the lecturer who taught computer science students answered, "like a nose to the head", which of the English phrases could be the same as "fits like a glove". Her experiences of using LbD have been mostly positive and it was clear that all participants and stakeholders usually always learn something new. However, this approach requires trust between the client, students and lecturers. She says the best thing about LbD is that it gives students a real touch to the company, its current state and development. From her point of view, problems in the implementation of the LbD approach can arise when its significance is not properly internalized and is only explored for project-based learning, even though the basis of $L b D$ is much broader. In her opinion, the purpose of LbD should also be more open to students, because with this study module implementation, when students were told more about it at the beginning of the studies, students had a better understanding of $\mathrm{LbD}$ and its use as Laurea more generally.

According to two business management lecturers, $L b D$ is also very well suited as a teaching method for the Service Design study module. In their view, it is suitable for almost all teaching, with the possible exception of some specific theory-focused studies. Their experiences have also been largely positive and students have generally liked learning according to the $\mathrm{LbD}$ approach. The challenge, they reported, is sometimes that it is often not possible to give any exact specs at the beginning of a study module about what will be done during it, as genuine client projects can be quite surprising. This can feel challenging and stressful for students if they are not used to this way of studying and working. Not all assessment criteria are very unambiguous in such study modules, as the study module may not have points on some pre-agreed scale. This can sometimes seem challenging for students, especially if they are very gradual-oriented and have not internalized a competency-based assessment model.

A thematic interview was also conducted for the clients who participated in the study module, in order to get information about their experiences using the $\mathrm{LbD}$ action model in their projects. Six customer interviews were conducted, which were also conducted remotely, and the interviews were transcribed for more detailed analysis. Only a few of the client's representatives had previous experience of participating in this type of collaboration. At the beginning of the study module, clients were told what the $\mathrm{LbD}$ is about and how the $\mathrm{LbD}$ action model is applied in practice in their projects. Clients were told that their active participation in project work in collaboration with students is paramount to achieving project goals. The clients understood this well, but the interview responses show that their own participation was not always as active as it should have been, due to their own schedule. The clients were very committed to the project, but other responsibilities sometimes caused problems in communicating with student groups. Despite small time problems, customers found the experience of this type of collaboration positive and the results useful. Clients were also asked to rate group scores on a scale of 1-10. Some groups received quite high scores from customers and the outputs of some groups did not reach such a high level. Despite how good a score each group received from customers, the results of all groups were perceived as useful by customers. Some of the outputs were also those that the customer can directly utilize in the development of their business and some of the outputs were those that can be used as a basis for further development. All customers felt that participating in this collaboration was a positive and good experience.

\section{CONCLUSIONS}

In summary, the LbD approach would appear to be a good and appropriate way for computing studies in the opinion of the majority of students surveyed. Especially for the Service Design study module, it seemed to fit well with the students. In the opinion of several students, the LbD appropriately combines theory and its application in practice, which deepens competence.

Students' experiences with the LbD approach were generally positive, with a few exceptions. Many students also felt that their skills had developed in a number of different areas during the study module, which reinforces the notion that the $\mathrm{LbD}$ is also well suited as a computing students' learning method. The issues related to competence development were derived from Laurea's strategy for 2030 and were therefore wide-ranging, so some of the areas of competence included in it are also those that are not directly included in the objectives of the Service Design module.

The lecturers' experiences were also largely positive and they all felt that the LbD is well suited as a learning method for the Service Design study module and also for computing studies. The clients' experiences of participating in such a collaborative project, according to the LbD action model, in which 
students, lecturers and clients participate together in a genuine project based on working life, were positive. Customers also felt that they received valuable returns from the projects, which they could either directly utilize or further process. The students' views also provided customers with added value, and 'outside the box' thinking.

\section{REFERENCES}

[1] K. Raij. Learning by Developing. Vantaa, Laurea, 2007.

[2] K. Raij. Summarising the basis of $\mathrm{LbD}$ for further development - review. Laurealaisella väylällä. 2012.

[3] E. Ferrance. Action Research. Themes in Education. Northeast and Islands Regional Educational Laboratory, Brown University, 2000.

[4] K.S.Taber. Action Research and the Academy: seeking to legitimise a 'different' form of research Teacher Development, 17(2), pp. 288 - 300, 2013.

[5] R. Sagor. Guiding School Improvement with Action Research. Association for Supervision and Curriculum Development. Alexandria, USA, 2000.

[6] J. Eskola \& J. Suoranta. Johdatus laadulliseen tutkimukseen. 7. painos. Tampere, Vastapaino, 2005.

[7] S. Hirsjärvi, P. Remes \& P. Sajavaara. Tutki ja kirjoita. 10 osin uud. laitos. Helsinki, Tammi, 2004.

[8] K. Ojasalo. Introduction - Learning by Developing in the open networked, digital world in Learning by Developing 2.0 - Case studies in theory and practice. (S. Juvonen, P. Marjanen \& T. Meristö eds.), pp. 6 - 13, Helsinki, PunaMusta Oy, 2019.

[9] Strategy 2030 of Laurea University of Applied Sciences. Accessed 20 September 2020. Retrieved from https://intra.laurea.fi/en/laurea/organisation/strategy/Documents/Laurea\%20strategy2030.pdf 